\title{
LARVAS DE ANOPHELES (SUBGENERO KERTESZIA) THEOBALD 1905 ENCONTRADAS EM CRIADOUROS ARTIFICIAIS, NO ESTADO DO PARANÁ, BRASIL
}

\author{
Ennio Luz* \\ José Consolim* \\ Orlando Carlos Barbosa* \\ Pedro Barroso Torres*
}

\begin{abstract}
LUZ, E. et al. Larvas de Anopheles (subgênero Kerteszia) Theobald 1905 encontradas em criadouros artificiais, no Estado do Paraná, Brasil. Rev. Saúde públ., S. Paulo, 21:466-8, 1987.
\end{abstract}

RESUMO: Discute-se encontro de larvas de duas espécies de anofelinos do subgênero Kerteszia - An. (Ker.) cruzii e An. (Ker.) bambusicolus - em criadouros artificiais, no Estado do Paraná, Brasil.

UNITERMOS: Anopheles (Ker.) cruzii. Anopheles (Ker.) bambusicolus. Malária, transmissão. Ecololgia de vetores. Vigilância epidemiológica.
$O$ interesse e a importância dos anofelinos do subgênero Kerteszia como transmissores da malária, iniciaram-se com as suspeitas de $\mathrm{Lutz}^{9}$ (1903), Galli-Valerio ${ }^{7}$ (1904), e as posteriores confirmaçōes de Rozeboon e Laird $^{13}$ (1942), Amaral $^{1}$ (1942), Correa ${ }^{3}$ (1943), Coutinho e col. $^{4}$ (1943), entre outros.

Como é do conhecimento dos malariologistas brasileiros, os anofelinos desse sugênero têm como criadouros as águas coletadas por bromeliáceas, exceto o Anopheles (Kerteszia) bambusicolus cujos criadouros preferenciais são as águas existentes em internódios de bambu (Rachou ${ }^{12}$, 1958).

A distribuição geográfica do Anopheles (Kerteszia) bambusicolus Komp, 1937, compreende a Argentina, Brasil, Colômbia, Equador e Peru (Forattini $\left.{ }^{6}, 1962\right)$. No Brasil, Coutinho (1946), descreve o macho de material proveniente de Londrina/PR, ratificando a espécie. Em 1968 quando da realização de pesquisas entomológicas na região paranaense do Rio Paraná, capturamos um exemplar desse anofelino nas imediações da Foz do Rio São Vicente, Município de Santa Helena (Consolim e Galvão ${ }^{2}$ 1973). O An. (Ker.) bambusicolus no território nacional está restrito ao Paraná.

Embora as larvas desta espécie tenham sido encontradas em internódios de bambu por Komp $^{8}$ (1937) e Coutinho ${ }^{5}$ (1946), segundo
Forattini ${ }^{6}$ (1962) também podem ser encontradas em bromélias.

Com o advento da reinfestação de algumas cidades da região sudeste do Brasil pelo Aedes (Stegomyia) aegypti, a partir de 1978 foram programados, em diversas áreas do Estado do Paraná, os serviços de vigilância anti-aegypti.

Entre os municípios programados para esses serviços de vigilância foram incluídos os de Paranaguá, no litoral paranaense, e de Foz do Iguaçu, no extremo oeste do Estado.

1. Paranaguá - de um total de 28 larvas de culicídeos coletados em março de 1980 , em oito vasos de barro distribuídos pelos bairros da Costeira e Porto Pedro II, duas larvas eram de An. (Ker.) cruzii. Com 6 anos de pesquisa ininterrupta não foi mais encontrada a referida espécie.

A cidade de Paranaguá devido, em parte, ao incremento das exportações a partir dos anos 60 , vem experimentando uma expansão acima da média dos demais municípios do Estado. O crescimento, tanto habitacional como populacional, é observado principalmente nas áreas suburbanas. Os bairros Costeira e Porto Pedro II, ambos edificados sobre antigos manguezais, ocupam praticamente os setores leste e nordeste da cidade. Há muito inexistem, nesses bairros, os criadouros de Kerteszia, as bro-

\footnotetext{
* Superintendência de Campanhas de Saúde Pública - SUCAM - Caixa Postal 127 - 80000 - Curitiba, PR - Brasil.
} 
meliáceas. Destarte, a presença do inseto ali, tem duas origens:

a) São transportados por trens que procedem de Curitiba e descem a Serra do Mar, em cuja encosta se situam pequenas estações encravadas nas matas, ricas em bromélias e elevada densidade de Kerteszia.

b) Chegam por vôo direto a partir da Ilha da Cotinga e Ilha dos Valadares, situadas em linha reta, entre 1.677 a $2.260 \mathrm{~m}$, respectivamente, conforme verificaram Rachou e col.11 (1949). Assim, pelo menos parcelas das que em tais circunstâncias ali conseguem chegar, encontram após seus repastos, dificuldades de retorno às suas origens, o que induz a crer que as desovas a outros tipos de criadouros são uma decorrência dessas dificuldades e não propriamente a possíveis mudanças de hábito.

2. Foz do Iguaçu - em agosto de 1984, quando foram realizadas pesquisas de vigilância no âmbito de algumas habitações a uns cem metros no interior do Parque Nacional do Iguaçu, foi apanhada, num pneu abandonado, uma larva de $A n$. (Ker.) bambusicolus.

Em junho de 1985 novas larvas apareceram, das quais foram obtidos quatro adultos, dois machos e duas fêmeas. Em dezembro desse mesmo ano foram encontradas, de uma só vez, numa armadilha de pneu, 20 larvas que, entretanto, morreram antes de completarem o ciclo. Em julho deste ano (1986), foram apanhadas oito larvas, dando origem a quatro machos e quatro fêmeas. Este lote, constituído por larvas de $3 .^{\circ}$ e $4 .^{\circ}$ estádios, foi encontrado, também, num pneu abandonado nos fundos de um hotel, em área semi-descampada, a dois mil metros da orla do Parque Nacional. Acrescente-se, como dados complementares que, devido a baixa temperatura na ocasião, a eclosão do úlimo durou 31 dias desde a coleta no campo.

Os 12 exemplares adultos até agora conseguidos da espécie encontram-se no Laboratório de Entomologia do Distrito de Foz do Iguaçu, da SUCAM, e alguns doados à Faculdade de Saúde Pública da Universidade de São Paulo.

A situação geográfica, tipo de solo, vegetação e clima da regiāo de Foz do Iguaçu, estão detalhadas em Maack ${ }^{10}$ (1968). Em referência à cobertura florestal entre os rios $\mathrm{Pi}$ - quiri e Iguaçu, porém, verificaram-se grandes modificações nas duas últimas décadas. A mata pluvial-subtropical foi devastada na quase totalidade, exceto nos domínios do Parque $\mathrm{Na}$ cional do Iguaçu, com cerca de $185 \mathrm{mil}$ hectares. Não obstante as freqüentes incursões de lavradores ao sul, o governo ainda mantém preservada a situação ecológica, sobretudo nas proximidades das Cataratas do Iguaçu. Neste local a flora é rica em variedades. Segundo o Diretor do Parque, cerca de $30 \mathrm{mil}$ espécies já foram catalogadas. No que tange à presença de bambu, só se notou regular quantidade a mais de 4 mil metros dos pontos positivos, estando presentes em maior quantidade próximo ao vale do Rio Iguaçu e tornando-se cada vez mais escassos até desaparecerem por completo à medida que se afasta do rio. Seu encontro é comum com perfurações, contendo até $150 \mathrm{ml}$ de água. Os exames feitos em 60 coleções de internódios foram negativos para anofelinos, sendo coletadas 32 larvas de Sabethini, seis de Tricho prosopon digitatum, oito de Culex sp e cinco de Toxorhynchites sp.

Em referência às bromeliáceas nas imediações dos criadouros notou-se sua presença em regular quantidade. Um exame mais minucioso desses vegetais implicava sua destruição, o que foi evitado para a preservação ecológica, recomendada pela direção do Parque. Em anos anteriores, contudo, verificaçōes efetuadas em cerca de 80 plantas resultaram negativas para Anophelini.

Com relação às larvas encontradas em vasos de barro, na cidade de Paranaguá, parece resultar da falta de opção às desovas, em razão da ausência de bromélias nas localidades pesquisadas; e não propriamente a uma possível mudança de hábito do inseto, o que minimizam possíveis implicações epidemiológicas.

Já o An. (Ker.) bambusicolus, com os dados coligidos, pode-se pensar pela mudança de hábito desse anofelino. Os desmatamentos ocorridos na região, nos últimos 20 anos, falam a favor dessa tese. Entretanto, considerando-se que nenhuma larva foi encontrada em águas de bambu, numa área preservada, e a frequiência com que vem sendo detectadas em criadouros artificiais, parece indicar, no mínimo, uma maior valência ecológica desse díptero na área em questão. 
LUZ, E. et al. [Larvas of the Anopheles (sub-genus Kerteszia) Theobald 1905, found in artificial breeding pens, in the State of Paraná, Brazil]. Rev. Saúde públ., S. Paulo, 21:466-8, 1987.

ABSTRACT: The finding of larvas of two species of anofelini (Kerteszia) An. (Ker.) cruzii and $A n$. (Ker.) bambusicolus in artificial breeding pens, in the state of Paraná, Brazil, is discussed.

UNITERMS: Anopheles (Ker.) cruzii. Anopheles (Ker.) bambusicolus. Malaria, transmission. Ecology, vectors. Population surveillance.

\section{REFERENCIAS BIBLIOGRAFICAS}

1. AMARAL, J. Infecção natural do Nyssorhynchus (Kerteszia) cruzii e bellator (Diptera Culicidae). Folha méd., 15:1-9, 1942.

2. CONSOLIM, J. \& GALVÃO, J. T. Sobre os anofelinos do Rio Paraná. 1 - Dénsidade regime do Rio. Arq. Biol. Tecnol., 16:174-81, 1973.

3. CORREA, R. R. Da infecção natural el plasmodíase malárica no Anopheles ( $K$ ) cruzii D. K., 1908. Rev. Med., 27(110):47-57, 1943.

4. COUTINHO, J. O.; RACHOU, R. G.; RICCIARDI, I. Contribuição para o conhecimento dos transmissores de malária no Brasil $-A$. (K) cruzii e bellator. Arq. Hig., Rio de Janeiro, 13:115-27, 1943.

5. COUTINHO, J. O. Contribuição para o estudo do subgênero Kerteszia com a descrição do macho de Anopheles (Kerteszia) bambusicolus Komp, 1937. Livro de Homenagem a R. F. D'Almeida, (13:149-54, 1946.

6. FORATTINI, O. P. Entomologia médica. São Paulo, Faculdade de Higiene e Saúde Pública da USP, 1962. v. 1.
7. GALLI-VALERIO, B. Notes de parasitologie. Cbl. Bakt., I. Abt. Orig., 35:81-91, 1904.

8. KOMP, W. H. W. The species of the subgeneres Kertezia of Anopheles (Diptera, Culicidae). Ann. ent. Soc. Amer., 30:492-529, 1937.

9. LUTZ, A. Waldmosquitos und Waldmalaria. Cbl. Bakt., I. Abt. Orig., 33:282-92, 1903.

10. MAACK, R. Geografia física do Estado do Paraná. Rio de Janeiro, J. Olímpio, 1968.

11. RACHOU, R. G.; RICCIARDI, I.; LUZ, E. Dispersão ativa e passiva dos anofelinos do subgênero Kerteszia no litoral Paranaense. Rev. bras. Malar., 1:65-72, 1949.

12. RACHOU, R. G. Anofelinos do Brasil: comportamento das espécies vetores de malária. Rev. bras. Malar., 10:145-81, 1958.

13. ROZEBOON, L. E. \& LAIRD, R. G. Anopheles (Kerteszia) bellator Dyar \& Knab. As vector of malaria in Trinidad, British West Indies. Amer. J. trop. Med., 22:83-91, 1942.

Recebido para publicação em: 23/3/1987 A provado para publicação em: 13/5/1987 